\title{
Japanese Social Expenditure under Rapid Population Ageing
}

\author{
Tetsuo Fukawa \\ Institution for Future Welfare, Tokyo, Japan \\ Email: fukawa@ifwj.org
}

Received 23 October 2015; accepted 13 November 2015; published 16 November 2015

Copyright ( 2015 by author and Scientific Research Publishing Inc.

This work is licensed under the Creative Commons Attribution International License (CC BY). http://creativecommons.org/licenses/by/4.0/

(c) (i) Open Access

\begin{abstract}
Japan is suffering from low fertility for more than two decades, and Japanese social security system needs a structural reform to be more effective and sustainable. In this paper, we discussed structural issues in the Japanese social security system, which will provide the basis for containing social expenditure in Japan. Some Japanese benefits, such as child-rearing support and benefit for low income families as well as long-term care benefit, need to be increased. On the other hand, it is important to incorporate right incentives in the system for healthcare and LTC services, and new forms of solidarity are indispensable to make Japanese social security system sustainable.
\end{abstract}

\section{Keywords}

Social Expenditure, Population Ageing, Public Pension System, Public Healthcare System, Long-Term Care System, Solidarity

\section{Introduction}

The Japanese population is ageing rapidly with a very low fertility since the 1990s. This low fertility together with a long life expectancy makes it more serious and difficult to reform social security system in Japan. Japanese social security system, namely public pension system, public healthcare system, long-term care system, support for child-rearing, and social welfare system, in general needs a structural reform to be more effective and sustainable, but the process is under way with many difficulties.

Entire working population has been covered by the public pension system since 1961. Japanese public pension is a multi-tiered system. The first-tier is the Basic Pension, which provides a universal coverage. The Employees Pension Insurance (EPI) covers most of employees in private sector, although it does not cover most of part-time workers. The contribution to the EPI is 17.8 percent of earnings since October 2015, shared equally by employees and employers. The amount of old age pension received by retired employees is the sum of Basic 
Pension (Basic part) plus the earnings related part. For the elderly households, the share of public pension benefits to the total income was 69 percent in 2012, and about 60 percent of them depended completely on public pension. The expenditure on public pension was 11 percent of GDP in 2013. The importance of employersponsored pensions has been increasing due to public pension reforms in recent years.

Total population has been covered by public health insurance since 1961. How to deliver and finance healthcare services for the elderly has been always a key issue, and since 2008 those who are 75 years old or over have been covered by a program named Healthcare System for the Advanced Elderly. Patients are free to choose physicians and hospitals, although there is some restriction. Both inpatient and outpatient services are provided in Japanese hospitals. While hospitals can enjoy economy of scope, there is severe competition in outpatient services between hospitals and practitioners [1]. In order to correct excessive competition, it has been considered that hospitals should be classified by function and patient flow streamlined. Most healthcare services used to be reimbursed on an itemized fee-for-service basis, and the price of each service is specified in the Medical Fee Schedule (Note 1). The same nationwide fee schedule is applied to practitioners and hospitals. The national healthcare expenditure was 8.3 percent of GDP in 2013.

The aging of the population has been increasing the demand for formal long-term care (LTC) services. This situation is exacerbated by increased female labor force participation and a cultural change as more women are questioning their traditional role as the primary family caregivers, particularly for their husband's parents [2]. The LTC insurance has been implemented since April 2000. Informal care is still important, although the LTC insurance benefits have become indispensable for the frail elderly. Many de facto institutional care services are provided under the name of home care services in Japan. Since the increase in the capacity of institutional care has been outpaced by the increase in the demand for them, most families have to wait for many months or years for the admission. The total LTC expenditure was 1.8 percent of GDP in 2014.

The local governments are mainly responsible for the welfare service delivery. However, there are 17 hundreds local governments in Japan with huge differences in terms of population, financial strength, administrative capability, etc.

This paper aims to identify structural issues in the Japanese social security system from national and international perspectives. These issues are mutually related, and the purpose of this paper is not to make an exhaustive list of issues but to identify some issues, which we believe will provide the basis for containing social expenditure in Japan and may provide implications for social security reforms in other developed countries.

\section{Japanese Social Expenditure from International Perspective}

The relation between ageing rate (the proportion of those aged 65 or over to the total population) and social expenditure as percent of GDP is quite different among developed countries. Figure 1 shows ageing rate in $\mathrm{X}$ Axis and social expenditure as percent of GDP in Y Axis for 6 countries during 1980-2014 for 5-year interval. Japanese social expenditure through public programs was 23.1 percent of GDP in 2011, compared to 31.9 percent in France, 28.1 percent in Sweden and 25.8 percent in Germany in 2014. The ageing process is quite remarkable in Japan, with a consecutive increase in social expenditure. Compared to Japan, increase in social expenditure is rapid in France and Sweden, with a relatively mild increase in ageing rate. German social expenditure has remained at 26 to 27 percent of GDP during 1995-2014. The Japanese aging rate is the highest since 2000, but Japanese social expenditure level has always been lower than that of USA (Note 2).

Table 1 shows social expenditure by branch in 2011 for 6 countries. This table contains various definition problems, and simple comparison is sometimes misleading. However, it is safe to say that Japanese social expenditure looks very much biased towards the elderly. There seems to be little room in Japan to increase public pension benefit. Japan is suffering from low fertility for more than two decades, but family benefit in Japan is still quite low after many laws and measures since 1990. Benefits for low income families and handicapped are also quite low in Japan.

\section{Structural Issues in the Japanese Social Security System}

1) Public pension system

The Japanese population is already among the most aged in the OECD countries, and ageing rate is 26 percent in 2014 (Table 2). According to the latest population projection in 2012, total population will be 97 million and ageing rate will be 39 percent in 2050, with fertility rate below 1.4 in future (Table 2). The projection results 


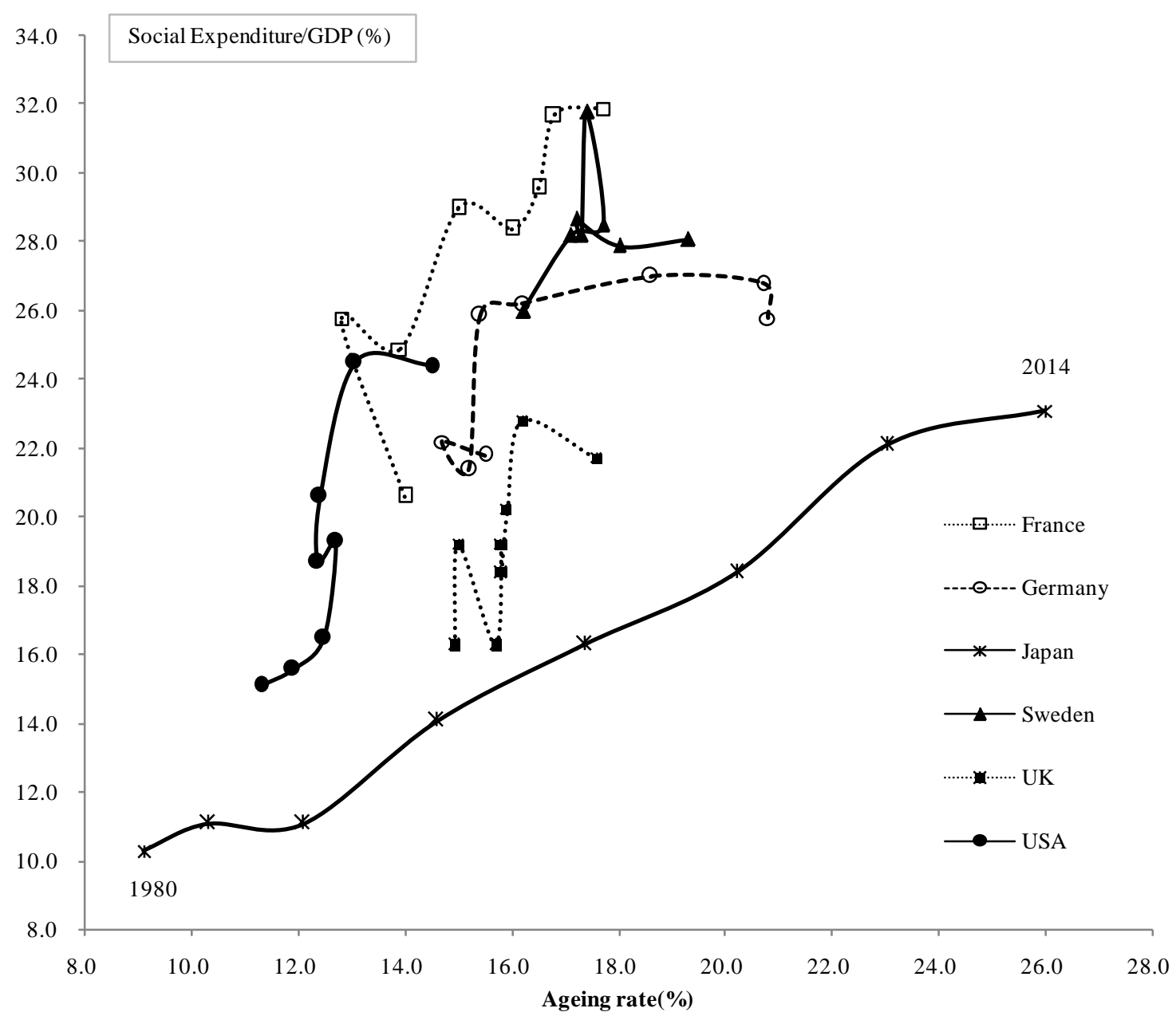

Figure 1. Aging rate (X axis) and social expenditure/GDP (Y axis) in 6 countries: 1980-2014. Source: OECD Health Data 2015 and OECD Social Expenditure Database 2015.

Table 1. Social expenditure by branch: 2011.

\begin{tabular}{|c|c|c|c|c|c|c|}
\hline & \multicolumn{6}{|c|}{ (\% of GDP) } \\
\hline & France & Germany & Japan & Sweden & UK & USA \\
\hline Old age & 12.5 & 8.6 & 10.4 & 9.4 & 6.1 & 6.0 \\
\hline Survivors & 1.7 & 2.0 & 1.4 & 0.4 & 0.1 & 0.7 \\
\hline Incapacity related & 1.7 & 2.0 & 1.0 & 4.3 & 2.5 & 1.4 \\
\hline Health & 8.6 & 8.0 & 7.7 & 6.7 & 7.7 & 8.0 \\
\hline Family & 2.9 & 2.2 & 1.4 & 3.6 & 4.0 & 0.7 \\
\hline Active labour market & 0.9 & 0.8 & 0.2 & 1.2 & 0.4 & 0.1 \\
\hline Unemployment & 1.6 & 1.2 & 0.3 & 0.4 & 0.4 & 0.8 \\
\hline Housing & 0.8 & 0.6 & 0.1 & 0.4 & 1.5 & 0.3 \\
\hline Others & 0.6 & 0.2 & 0.5 & 0.7 & 0.2 & 0.9 \\
\hline Total & 31.4 & 25.5 & 23.1 & 27.2 & 22.7 & 19.0 \\
\hline
\end{tabular}

Source: OECD Social Expenditure Database 2015. 
Table 2. Trends of population and social security benefits in Japan: 1960-2050.

\begin{tabular}{|c|c|c|c|c|c|c|c|c|c|c|c|c|c|c|}
\hline \multirow{2}{*}{ Year } & \multicolumn{3}{|c|}{ Population } & \multirow{2}{*}{$\begin{array}{c}\text { Threshold } \\
\text { age a }\end{array}$} & \multirow{2}{*}{ TFR } & \multirow{2}{*}{$\begin{array}{c}\text { Life } \\
\text { expect } \\
\text { (year) }\end{array}$} & \multicolumn{8}{|c|}{ Social security benefits as \% of GDP } \\
\hline & $\begin{array}{c}\text { Total } \\
\text { (million) }\end{array}$ & $\begin{array}{l}65+ \\
(\%)\end{array}$ & $\begin{array}{l}70+ \\
(\%)\end{array}$ & & & & Total & & Health & & Pension & & LTC & \\
\hline 1960 & 93.4 & 5.7 & 3.4 & 59.0 & 2.00 & 67.8 & 3.9 & & 1.8 & & & & & \\
\hline 1970 & 103.7 & 7.1 & 4.2 & 60.6 & 2.13 & 72.0 & 4.7 & & 2.8 & & 1.1 & & & \\
\hline 1980 & 117.1 & 9.1 & 5.7 & 63.1 & 1.75 & 76.1 & 10.0 & & 4.3 & & 4.2 & & & \\
\hline 1990 & 123.6 & 12.1 & 7.9 & 65.1 & 1.54 & 78.9 & 10.5 & & 4.1 & & 5.3 & & & \\
\hline 2000 & 126.9 & 17.4 & 11.8 & 66.3 & 1.36 & 81.2 & 15.3 & & 5.1 & & 8.1 & & 0.6 & \\
\hline 2010 & 128.1 & 23.0 & 16.6 & 68.0 & 1.39 & 83.0 & 21.8 & & 6.9 & & 11.0 & & 1.6 & \\
\hline 2014 & 127.1 & 26.0 & 18.8 & 68.5 & 1.42 & 83.7 & 23.0 & b & 7.3 & b & 11.4 & b & 1.8 & b \\
\hline 2025 & 120.7 & 30.3 & 24.5 & 69.4 & 1.33 & 84.8 & 24.4 & & 8.8 & & 9.9 & & 3.2 & \\
\hline 2050 & 97.1 & 38.8 & 32.0 & 70.9 & 1.35 & 86.9 & $\cdots$ & & $\ldots$ & & $\ldots$ & & $\ldots$ & \\
\hline
\end{tabular}

Note: a) Threshold age means that the proportion of those who are at this age or over is 20 percent of the total population under the stable population at the Life Table of each year; b) 2012; c) Social security benefits in 2025 are based on MHLW (2012). Source: IPSS (2012) and IPSS (2014). Ministry of Health, Labour and Welfare, Life Table each year.

may change with different fertility assumption, but Japan is already the front runner in coping with containing expenditures which increase in line with population ageing. In order to contain public pension expenditure, clear options are to raise the eligibility age further beyond 65 years old, to change the post-retirement indexation of benefits, to improve the management of the assets held by the state pension funds in order to raise the rate of return, and finally to reduce the rate at which pension benefits accrue.

Normal pension age is 65 years old for the Basic Pension, but concerning the EPI it will be 65 in 2025 for male and 2030 for female. Japan is lagged behind in increasing pension age in line with extension of life expectancy. In this connection, we calculated a threshold age shown in Table 2 . If we define the elderly as the oldest 20 percent of the population based on the stable population in the Life Tables, then the threshold age for the elderly was 59 years old in 1960, 68.5 in 2014 and will be 71 years old in 2050. Therefore, it might be more reasonable to increase pension age from 65 to 69 rather soon. Indeed, new ageing rate (the proportion of those aged 70 or over to the total population) will be 32 percent in 2050, which makes public pension reform more feasible.

More significant reform of the public pension system in Japan is to reduce the extent of the inter-generational differences in the internal rate of return from the system that occurs in the current pay-as-you-go system. This could be accomplished partially by fixing the contribution rate over a long time. The tax treatment of pension benefits should be aligned with that of income from employment. The social security system would become more sustainable if the labor force participation of women and the elderly were to increase, and public pension system should be more oriented contributing toward this direction.

2) Public healthcare system

Although Japanese healthcare expenditure as percent of GDP is low compared to the other developed countries, financing of healthcare system especially for the elderly is still a serious issue and many problems have been revealed in healthcare delivery recently.

Japanese healthcare reforms in the 1990s featured the pursuit of quality (such as informed consent and patient's choice) as well as cost-containment. It has been more focused on the sustainability of the system and patients-oriented healthcare in the 2000s and 2010s. The main reform issues in the Japanese healthcare system are: a) reorganization of health service delivery system; b) co-ordination between primary care and hospital care as well as between healthcare and long-term care; c) quality assurance of health services and empowerment of patients.

Elderly tend to suffer from multiple chronic diseases and their functional ability tends to decrease with age. Per capita healthcare expenditure for those who are 65 or over is 4 times than that for 0 - 64 age group (Figure 2), and elderly patients stay much longer in hospitals in Japan. As a result, 58 percent of the national health expenditure is consumed by those who are aged 65 or over and 47 percent by those who are aged 70 or over in 


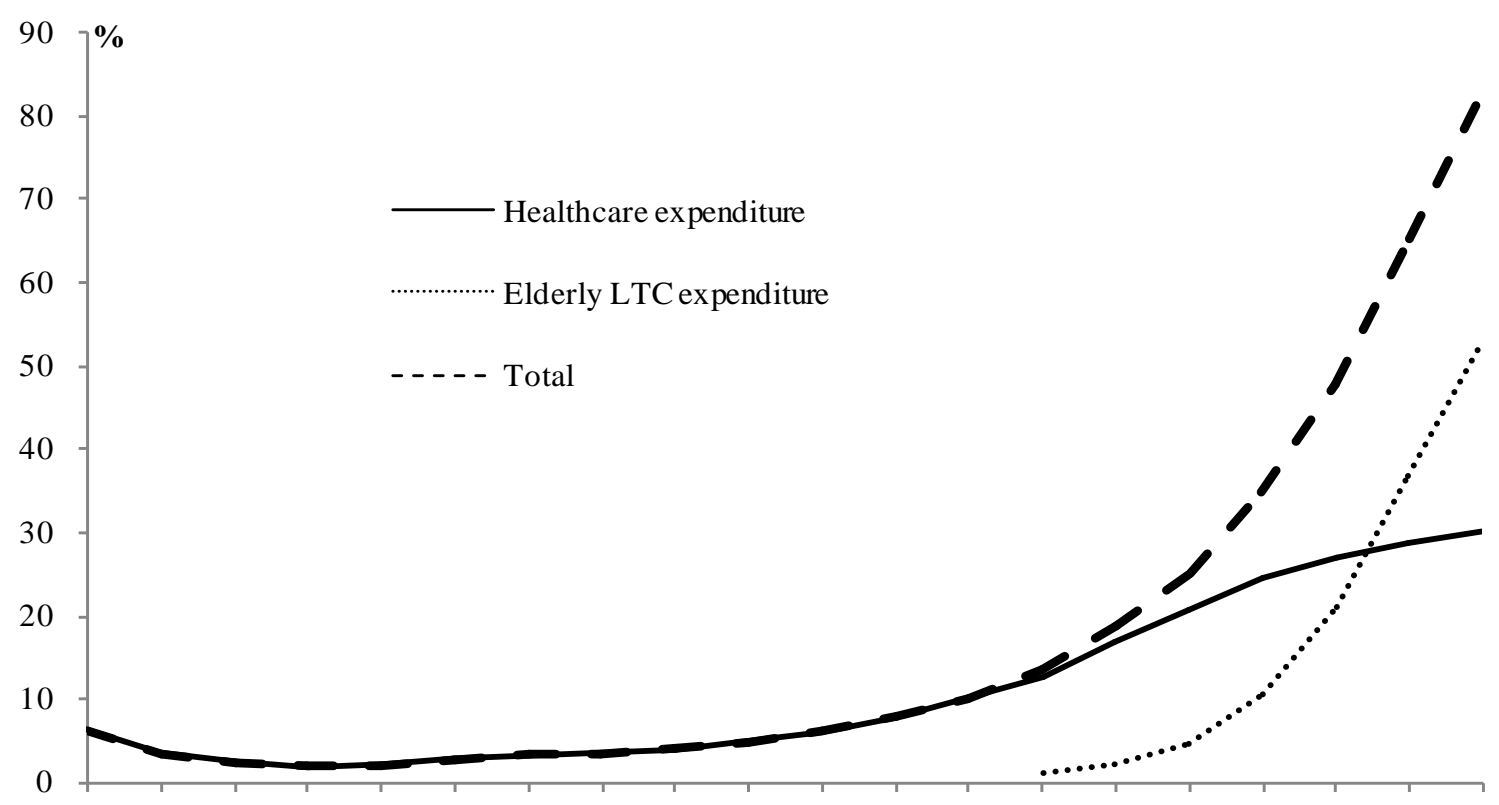

0- 5- 10- 15- 20- 25- 30- 35- 40- 45- 50- 55- 60- 65- 70- 75- 80- 85- 90- 95+

Age group

Figure 2. Per capita healthcare expenditure and elderly LTC expenditure as percent of per capita GDP by age group in Japan: 2013. Source: author's calculation based on the data from Ministry of Health, Labor and Welfare.

2013 [3]. The focuses of reforming the healthcare system for the elderly are always a) coordination between healthcare services and long-term care services and b) elimination of inappropriate long-term hospitalization.

A new insurance scheme for those over the age of 75, introduced in 2008, together with policies to reduce the demand for healthcare by preventing lifestyle-related diseases are expected to help keep healthcare expenditure stable. However, per capita healthcare expenditure for 85 years old or over is increasing again in recent years, and public health insurance will have to be trimmed further due to financial constraints. Japanese health insurance in general has so far paid relatively little attention to preventive care. However, in view of the importance of lifestyle-related diseases, prevention has become one of the main issues in recent healthcare reforms.

3) Long-term care system

The principles of Japanese LTC Insurance are universality of coverage (although benefits are available mainly for the elderly), financing through social insurance (although the public fund finances 45 percent of the cost), freedom of choice by service users, and reliance on a service market.

The existence of so-called "bedridden elderly" has been a peculiar phenomenon in Japan. There had been frequent use of hospital beds instead of long-term care facilities in Japan, because: a) the accessibility to the latter was limited, and b) the medically oriented services were readily accessible to the elderly [2]. However, after the implementation of the LTC insurance, the number of so-called socially induced hospitalization cases especially among elderly patients has been reduced, although not totally eliminated.

There is still a significant shortage of institutional care services, and it is necessary to encourage the development of a private market of the LTC providers especially for institutional care. It is quite natural from the consumers' point of view to demand coordination between healthcare and LTC services. However, there is some strong concern that the system will be dominated by a medical model with individuals who are not familiar with the LTC.

Healthcare expenditure for the elderly (those who are 65 years old or over) is about 3 times larger than elderly LTC expenditure. However, Figure 2 clearly shows that restricting to those who are 90 years old or over, LTC expenditure is larger than healthcare expenditure.

\section{Discussion}

Although the 2004 pension reform was a large scale reform, setting upper ceiling of the contribution rate and in- 
troducing a mechanism (Note 3) adjusting beneficiary-contributor imbalance. However, many problems still remain unsolved. Japanese public pension system needs to be less vulnerable to economic and demographic changes. Introduction of individual retirement account, for example, may be useful towards this purpose. However, reform principles are not yet reached to a broad national consensus. The most important factors for the sustainability of the public pension system are fairness of the system and public trust to the system.

People's preference for equality is strong in Japan especially for healthcare services. The right incentive structure is crucial for the sustainable development of the healthcare system. The reform of the reimbursement system is especially important to place the right incentives in the system. The key to achieving higher quality and greater efficiency in healthcare, as well as in long-term nursing care, is to make greater use of the dynamism of the private sector, in part by allowing companies to manage hospitals and nursing homes [4]. Towards this end, prevention and the empowerment of patients are gaining importance in Japan. Priority has been given so far to cure rather than prevention and to equal access to services in Japanese healthcare delivery, but the need to balance patients' freedom and cost containment makes it necessary to consider the so-called gate-keeping function of primary care physicians and to focus more on prevention of lifestyle-related diseases [5]. Prevention is important not only for averting cost-push pressures to health expenditure but also for people's quality of life [6].

As population is aging, how to provide LTC for the frail elderly is a mounting concern in the developed countries. The need for LTC is quite common among the very old. It is quite a remarkable event in Japan that the provision of LTC has been changed from welfare and rationing services to needs-based insurance benefits. LTC for the elderly is related not only to the dignity of the individual elderly but also to the "shape" of a society. As LTC expenditure is more sensitive to the aging of the population than healthcare expenditure as seen in Figure 2, it is indispensable to prevent and reduce the incidence of LTC as much as possible. Coordination between healthcare and LTC services is always a sticking problem. Financing of LTC services is still one of key issues, and in this regard a new balance between solidarity and self-help is still important, because the cost of aged society will never disappear in any case [2].

Financing of the social expenditure such as LTC benefit, family benefit, benefit for low income families and benefit for handicapped is still one of the key issues in Japan, and new options have been reviewed, including broadening the financing basis of social benefits, integration of public systems and private arrangements, and redefinition of the elderly. Under the circumstances of trimming public programs, curtailment of fringe benefits by company, and enlargement of individual responsibility, new forms of solidarity including a fair share of contribution by the elderly is indispensable. Concerning a redefinition of the elderly, Japanese experience provides an interesting example. In view of threshold ages shown in Table 2, a cautious approach has been taken in introducing a healthcare program for the elderly, but extension of pension age is very slow and lagged behind compared to the other developed countries. Even if the burden on social security (tax, contribution, and utility charge) is reduced, curtailed social protection should be complemented by individual efforts, because the cost of old age will not disappear. In reducing the generosity of aging-related programs, a balanced reform is needed: spread the cost of reform equitably across generations; improve the willingness to save for retirement; and consider the impact of reform on low-income households [7].

Solidarity between patients and non-patients remains the same, but solidarity between young and old may be changing [6]. Whether to attach importance on solidarity or on self-help is not a matter of choice but a matter of weight. As Japan is already a front runner in coping with containing age-related social expenditure, new forms of solidarity are indispensable to make Japanese social security system sustainable. If people pay more attention to lifestyle-related diseases and refrain from over-use of healthcare services, then healthcare system may escape from too heavy pressure and contribution rate may remain stable. If people have independent spirit and not easily use LTC services, then LTC expenditure may not increase too much. If public pension system does not leave low earning workers behind, then public assistance may avoid steep increase in the number of applicants eventually. Each country gropes for a better balance between solidarity and individual responsibility, but there is so far no national consensus on this issue in Japan [8].

We discussed structural issues in the Japanese social security system, which will provide the basis for containing social expenditure in Japan. The followings are summary of our discussion:

- Ageing of the population is and will be very severe in Japan. However, future fertility rate may change according to policy and environment, and social support for child-rearing should be done more seriously;

- Other than family benefit, benefits for low income families and handicapped as well as LTC benefit need to be increased, which of course require additional resources. Future public pension benefit is anticipated to be 
stable, but it is not certain because of political power of the elderly;

- For healthcare and LTC services, it is especially important to incorporate right incentives in the system; and

- New forms of solidarity, including fair share of burden among generations, are indispensable in order to make Japanese social security system sustainable.

\section{Conclusion}

The environments of Japanese social security system will change significantly if fertility rate will increase and threshold age for the elderly will be increased. However, further structural reforms are still necessary, and new forms of solidarity are indispensable to make Japanese social security system sustainable.

\section{Notes}

(Note 1) Benefit packages do not allow the mixed use of listed items in the Medical Fee Schedule and nonlisted items in Japan. For example, whenever advanced technology that is not covered by health insurance is applied, the total costs are treated as ineligible for insurance coverage. This is called the prohibition of mixed use. However, under the high-cost relief scheme, if a patient receives certain high-technology treatments in specially approved medical facilities, the basic part corresponding to the listed conventional health service is covered by the insurance, and the patient should pay the balance.

(Note 2) Social expenditure in the USA was modified as if there were a public health insurance covering most of the population, like most other developed countries.

(Note 3) This mechanism is called "macro economy slide (indexation of benefit)".

\section{References}

[1] Fukawa, T. (2005) Some Structural Issues in the Japanese Social Security System. The Japanese Journal of Social Security Policy, 4, 67-75.

[2] Fukawa, T., Ogura, S. and van den Berg, B. (2012) Overview of Financing and Managing Long-Term Care Services in Six OECD Countries. Japanese Journal of Health Economics and Policy, 24, 1-7.

[3] MHLW (2015) National Healthcare Expenditure for FY 2013. (In Japanese)

[4] OECD (2006) OECD Economic Surveys 2006 Japan.

[5] Fukawa, T. (2009) Healthcare Expenditures in Japan and France. The Japanese Journal of Social Security Policy, 8, 68-76.

[6] Fukawa, T. (2007) Macro Evaluation of the Japanese Healthcare System in Comparison with Germany. The Japanese Journal of Social Security Policy, 6, 31-42.

[7] OECD (2003) Policies for an Ageing Society: Recent Measures and Areas for Future Reform. Economics Department Working Paper No.369.

[8] Oshio, T., Tajika, E. and Fukawa, T. (2014) Social Security Policies in Japan: Issues and Challenges. University of Tokyo Press, Tokyo. (In Japanese) 